\title{
Human ROBO1 Regulates Interaural Interaction in Auditory Pathways
}

\author{
Satu Lamminmäki, ${ }^{1}$ Satu Massinen, ${ }^{2 \star}$ Jaana Nopola-Hemmi, ${ }^{3 \star}$ Juha Kere, ${ }^{2,4}$ and Riitta Hari ${ }^{1,5,6}$ \\ ${ }^{1}$ Brain Research Unit, O.V. Lounasmaa Laboratory, School of Science, Aalto University, FI-00076 AALTO, Espoo, Finland, ${ }^{2}$ Research Program's Unit, \\ Molecular Medicine and Department of Medical Genetics, University of Helsinki, and Folkhälsan Institute of Genetics, FIN-00014 Helsinki, Finland, \\ ${ }^{3}$ Division of Child Neurology, Department of Gynecology and Pediatrics, Jorvi Hospital, University Central Hospital, FIN-00029 Espoo, Finland, \\ ${ }^{4}$ Department of Biosciences and Nutrition, Center for Biosciences, and Science for Life Laboratory, Karolinska Institutet, SE-14157 Stockholm, Sweden, \\ ${ }^{5}$ Advanced Magnetic Imaging Centre, School of Science, Aalto University, FI-00076 AALTO, Espoo, Finland, and ${ }^{6}$ Department of Clinical Neurophysiology, \\ Helsinki University Central Hospital, FI-00029 Helsinki, Finland
}

In rodents, the Robol gene regulates midline crossing of major nerve tracts, a fundamental property of the mammalian CNS. However, the neurodevelopmental function of the human $R O B 01$ gene remains unknown, apart from a suggested role in dyslexia. We therefore studied axonal crossing with a functional approach, based on magnetoencephalography, in 10 dyslexic individuals who all share the same rare, weakly expressing haplotype of the $\mathrm{ROBO1}$ gene. Auditory-cortex responses were recorded separately to left- and right-ear sounds that were amplitude modulated at different frequencies. We found impaired interaural interaction that depended on the ROBO1 in a dosedependent manner. Our results indicate that normal crossing of the auditory pathways requires an adequate $R O B O 1$ expression level.

\section{Introduction}

In the mammalian CNS, brain commissures and a significant part of the afferent and efferent pathways cross the midline. A key regulator of an analogous axonal crossing in the fruit fly, Drosophila, is the robo receptor (Seeger et al., 1993; Kidd et al., 1998a,b) that binds the chemorepulsive ligand slit at the midline (Brose et al., 1999; Kidd et al., 1999). In the rodent nervous system, orthologous Robo1 and Robo2 genes (Kidd et al., 1998a) and a structurally divergent Robo3 gene (Yuan et al., 1999) are expressed. In humans, mutations of $\mathrm{ROBO} 3$ impair crossing of somatosensory and motor pathways, as was demonstrated in patients with a syndrome of horizontal gaze palsy with progressive scoliosis (Jen et al., 2004; Sicotte et al., 2006; Avadhani et al., 2010; $\mathrm{Ng}$ et al., 2011). However, the neurodevelopmental roles of the human $\mathrm{ROBO} 2$ and $\mathrm{ROBO} 1$ genes remain unclear, apart from the suggested involvement of $R O B O 1$ in dyslexia (Hannula-Jouppi et al., 2005) and possibly in autism (Anitha et al., 2008); the linkage between dyslexia and the genomic region (3p13) near ROBO1 has

Received Aug. 4, 2011; revised Nov. 17, 2011; accepted Nov. 23, 2011.

Author contributions: S.L., S.M., J.N.-H., J.K., and R.H. designed research; S.L., S.M., and J.N.-H. performed research; S.L., S.M., J.K., and R.H. analyzed data; S.L., S.M., and R.H. wrote the paper.

This work was supported by the Academy of Finland (National Centers of Excellence Programme 2006-2011), the Sigrid Jusélius Foundation, the Signe and Ane Gyllenberg Foundation, the Päivikki and Sakari Sohlberg Foundation, and the Helsinki Biomedical Graduate School. We thank K. Hannula-Jouppi for comments on gene expression analysis, P. Saavalainen for providing the control samples for expression analysis, J. Kainulainen and R. Lehtinen for technical assistance, and C. Nangini for checking the language.

*S.M and J.N.-H. contributed equally to this work.

The authors declare no competing financial interests.

Correspondence should be addressed to Satu Lamminmäki, Brain Research Unit, 0.V. Lounasmaa Laboratory, School of Science, Aalto University, P.O. Box 15100, Fl-00076 AALT0, Espoo, Finland. E-mail: satu. lamminmaki@aalto.fi.

DOI:10.1523/JNEUROSCI.4007-11.2012

Copyright $\odot 2012$ the authors $\quad 0270-6474 / 12 / 320966-06 \$ 15.00 / 0$ also been demonstrated in a large genome-wide scan (Fisher et al., 2002). All homozygous Robo1 knock-out mice died at birth and displayed large tight fascicles of non-crossing callosal axons, whereas the anatomic structures of heterozygous Robo1 ${ }^{+/-}$mice seemed normal (Andrews et al., 2006).

Because no homozygous human $\mathrm{ROBO1}$ mutations are available, we recruited members of a Finnish family (see Fig. 1) in whom a rare but specific, weakly expressing haplotype of $\mathrm{ROBO1}$ (Hannula-Jouppi et al., 2005) cosegregates with dyslexia in a dominant manner (Nopola-Hemmi et al., 2001). Because dyslexia associates with various auditory disorders (Hari and Renvall, 2001) and because animal studies suggest minimal anatomical abnormalities in individuals with non-total $R O B O 1$ defect, we applied a sensitive electrophysiological biomarker of functional crossing in auditory pathways.

Normally, the majority of axons from each ear cross the midline at several levels and reach the contralateral auditory cortex, whereas the rest project to the ipsilateral side (see Fig. $2 A$ ). Thus, the auditory cortices of each hemisphere receive input from both ears. Cortical steady-state responses to sounds from one ear are weaker during binaural than monaural listening, indicating binaural suppressive interaction (Fujiki et al., 2002; Kaneko et al., 2003). The suppression is stronger for ipsilateral than contralateral sounds and requires convergence of the inputs from both ears somewhere in the auditory pathways. We thus hypothesized that weaker crossing of axons as a result of deficient $R O B O 1$ functioning would manifest as decreased binaural suppression of the ipsilateral responses. An auditory pathway from the ipsilateral ear to the cortex does not cross the midline itself, and thus the convergence, and the binaural suppression, has to rely on the crossing axons from the opposite side.

We studied binaural suppression - and thereby indirectly the strength of crossing in auditory pathways_-in individuals with 


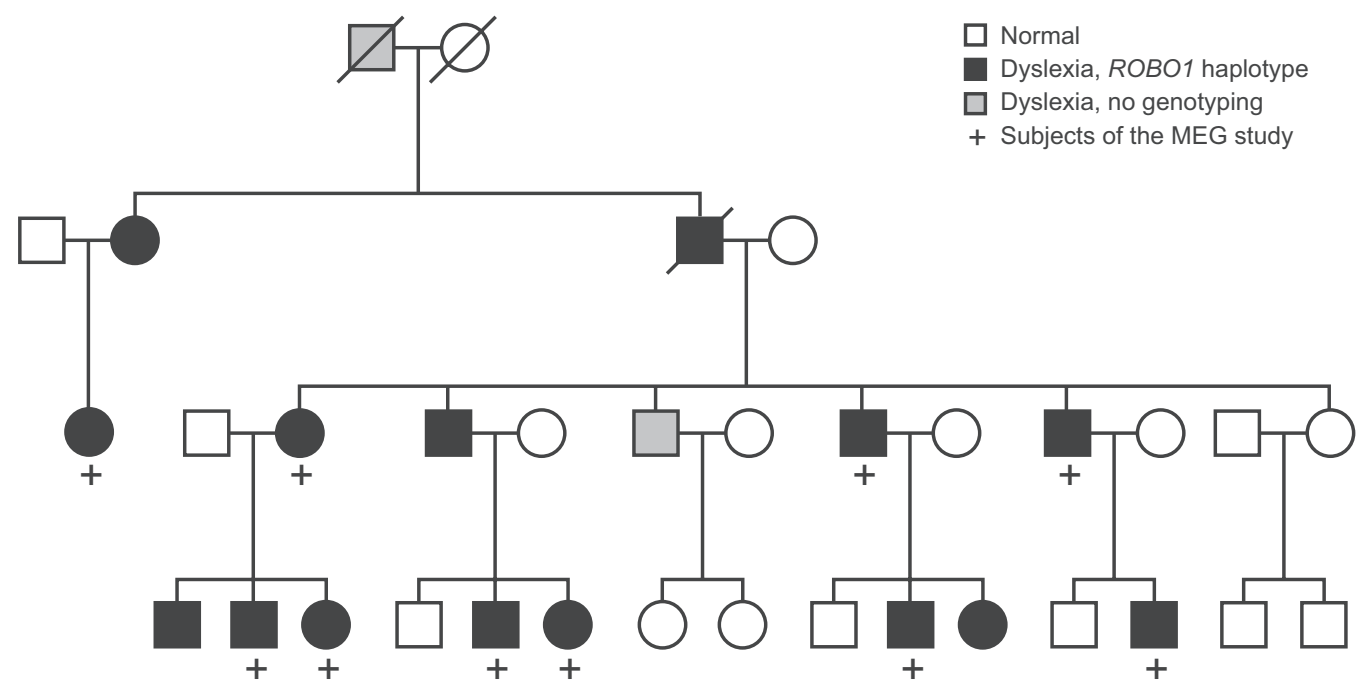

Figure 1. Abridged pedigree of the family carrying the weakly expressing haplotype of ROBO1. The haplotype cosegregates with developmental dyslexia in a dominant manner. Squares denote males and circles females.

the ROBO1 gene defect by "frequency-tagging" magnetoencephalographic (MEG) steady-state responses, a method used previously in nonclinical studies (Fujiki et al., 2002; Kaneko et al., 2003).

\section{Materials and Methods}

Subjects. The ROBO1 group comprised 10 dyslexic individuals (four females and six males; ages $19-51$ years; mean \pm SD, $31.0 \pm 12.3$ years) from a Finnish family (Fig. 1) (Nopola-Hemmi et al., 2002), all sharing the same rare, weakly expressing haplotype of the $R O B O 1$ gene that cosegregates with dyslexia in a dominant manner and has not been found in other families (Hannula-Jouppi et al., 2005). The haplotype covers the whole genomic area of $\mathrm{ROBO1}$; it is situated between the microsatellite markers D3S3039 and D3S3045 and includes two silent, single nucleotide polymorphisms (SNPs), one exonic insertion/deletion polymorphism and four SNPs in the 3' UTR in the ROBO1 gene (Nopola-Hemmi et al., 2001; Hannula-Jouppi et al., 2005). According the neuropsychological test results (Nopola-Hemmi et al., 2002), two subjects have severe dyslexia and five subjects have mild or compensated dyslexia. Three subjects were younger than 13 years of age at the time of neuropsychological testing; thus, the severity of their dyslexia was not categorized. Two of our 10 subjects had participated in the previous study (Hannula-Jouppi et al., 2005) who demonstrated attenuated expression level of the dyslexialinked allele (on average, $66 \%$ of the expression of the other allele). The control group in the MEG study comprised 10 healthy, non-dyslexic sexand age-matched individuals (ages $18-49$ years; mean \pm SD, $31.8 \pm 12.5$ years).

All subjects of the MEG experiment were right-handed (Edinburgh Handedness Inventory scores of 78.9-100 and mean of 94.7 for ROBO1 group; and scores of 76.5-100 and mean of 95.9 for controls). The audiograms were normal (within $20 \mathrm{~dB}$ hearing level) between 125 and $3000 \mathrm{~Hz}$ in every subject.

Because no blood samples from the MEG control group were available, preexisting samples of 10 anonymous healthy blood donors recruited by the Finnish Red Cross Blood Service were used as control data in the ROBO1 expression analysis.

The study protocol had previous permission from the local ethics committee, and all experiments were undertaken with the informed consent of the subjects.

The electrophysiological biomarker. Axonal crossing of auditory pathways was studied via binaural suppression using "frequency-tagged" stimuli, that is, left- and right-ear sounds amplitude modulated at different frequencies (Fig. 2B). The tagged auditory-cortex responses were selectively extracted from each hemisphere with magnetoencephalogra- phy with a method previously developed in our laboratory (Fujiki et al., 2002; Kaneko et al., 2003). By means of the modulation frequencies, MEG signals for the left and right-ear inputs of the binaural stimuli can be separated from each other and then compared with the monaural responses to quantify the binaural suppression.

The stimulation and analysis were based on previous nonclinical studies of frequency-tagged auditory inputs (Fujiki et al., 2002; Kaneko et al., 2003). We delivered, via plastic tubes and earpieces, continuous $1 \mathrm{kHz}$ tones that were amplitude modulated with $100 \%$ depth at $41.1 \mathrm{~Hz}$ in the left ear and at $39.1 \mathrm{~Hz}$ in the right ear (Fig. $2 B$ ). The three different stimuli (left monaural, right monaural, binaural) were repeated once and presented in random order across subjects. Each stimulus lasted for $120 \mathrm{~s}$, and the interstimulus interval was $5 \mathrm{~s}$.

Sound intensity was set at the loudest but still comfortable listening level (60-75 $\mathrm{dB}$ above the individual hearing threshold; mean \pm SEM, $70 \pm 1.5$ for $R O B O 1$ group and $71 \pm 1.4$ for control subjects); intensity changes have no effect on the magnitude of binaural interaction within the range of 45-75 dB sensation level (Kaneko et al., 2003) and thus to the focus of this study. The subjects were instructed to keep their eyes open during the experiment.

Brain signals were measured in a magnetically shielded room with a whole-scalp neuromagnetometer (Vectorview; Elekta Oy) containing 102 sensor units, each comprising one magnetometer and two orthogonal planar gradiometers. The raw data were filtered from 0.03 to $200 \mathrm{~Hz}$ and sampled at $600 \mathrm{~Hz}$. Traces contaminated by eye blinks and eye movements were rejected on the basis of a simultaneously measured vertical electro-oculogram.

MEG signals were averaged, time locked to the phase of the amplitude modulation; the analysis epochs comprised six modulation cycles, and altogether $\sim 2000$ epochs were averaged. Responses evoked by left- and right-ear inputs (both during monaural and binaural stimuli) were averaged, time locked to the 41.1 and $39.1 \mathrm{~Hz}$ modulation frequencies, respectively. The resulting steady-state responses (left monaural, right monaural, left binaural, right binaural) were bandpassed to $32-48 \mathrm{~Hz}$ by a non-causal FFT-based filter using a Hanning window. The filtering causes no phase shifts but dampens the outermost parts of the signal. We therefore used only the two middle cycles of the epochs of six cycles for signal strength quantification.

The steady-state responses to repeated stimuli were inspected for replicability and then averaged. Because of technical artifacts, no replication was available for one control subject and one $R O B O 1$ subject.

Because planar gradiometers show the maximum signal directly above an active brain area, gradiometer pairs of four adjacent sensor units, including the gradiometer with the maximum steady-state response, 
A

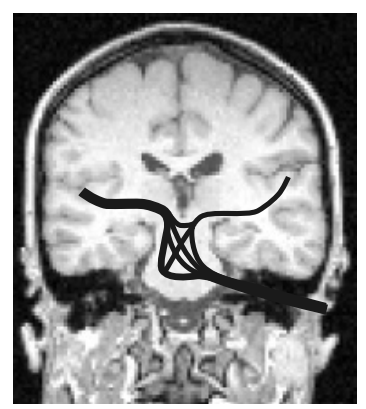

B

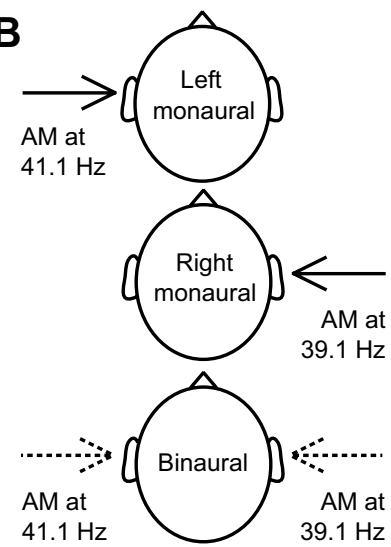

C
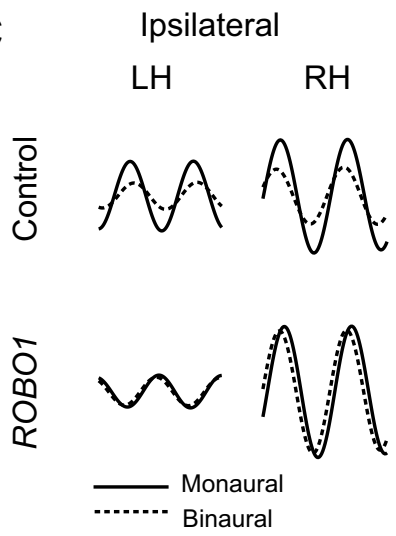

D

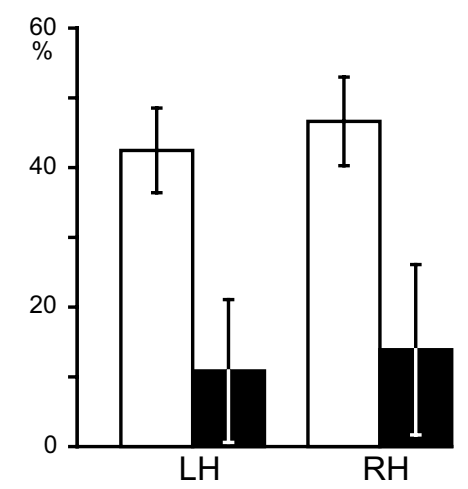

Contralateral

$\mathrm{LH} \quad \mathrm{RH}$
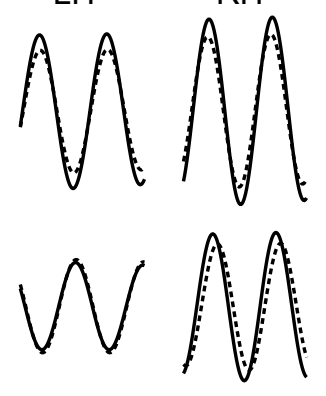

$[2 \mathrm{fT} / \mathrm{cm} \quad \overrightarrow{20 \mathrm{~ms}}$

Contralateral

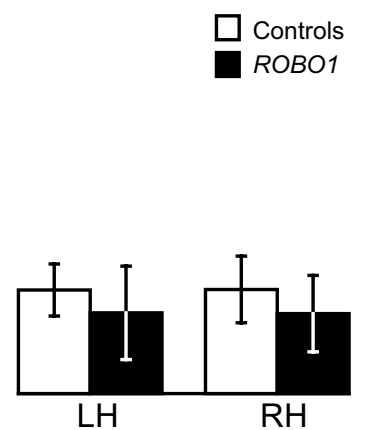

Figure 2. Electrophysiological assessment of the crossing of auditory pathways. $A$, A highly schematic presentation of the afferent tracts of the auditory system from the right ear. The majority of the axons cross the midline in the brainstem and enter the contralateral temporal cortex, whereas approximately one-third of the axons remain in the ipsilateral side. $\boldsymbol{B}$, The applied stimuli. Left monaural, right monaural, and binaural 1-kHz continuous, 2-min-long tones were presented, amplitude modulated (AM) at $41.1 \mathrm{~Hz}$ for the left ear and at $39.1 \mathrm{~Hz}$ for the right ear. C, Averaged steady-state responses (2 cycles illustrated) in a control subject (top row) and a ROBO1 subject (bottom row) to ipsilateral and contralateral inputs. Approximately 2000 single responses were averaged, time locked to the phase of the modulation; the traces were filtered from 32 to $48 \mathrm{~Hz}$. The same amplitude-modulated tone was presented monaurally (solid lines) and during binaural presentation (dashed lines; comparable with the arrows in $\boldsymbol{B}$ ). For binaural stimuli, responses to left- and right-ear inputs were extracted on the basis of different modulation frequencies of the stimuli. $\boldsymbol{D}$, Mean \pm SEM suppression of responses during binaural listening. Values indicate (in percentage) how much smaller the responses were in the binaural than in the monaural situation.

were used for quantifying the neural activity in the left and right auditory cortices. For each gradiometer pair, the vector sum of the two orthogonally measured steady-state responses was calculated (that is, at each time point, the squared values of both gradiometer signals were summed, and then the square root of the sum was computed); the vector sums of four gradient pairs were averaged. The maximum strengths of these mean vector sums (areal average responses) were determined separately in the left $(\mathrm{LH})$ and right $(\mathrm{RH})$ hemispheres, and strengths of responsesevoked by the same input in the same ear-were compared during binaural and monaural stimulation. Suppression of responses during binaural stimulation was reported as a percentage decrease from corresponding monaural response.

Additional source analysis was performed for 10 control subjects and for eight $\mathrm{ROBO} 1$ subjects in the $\mathrm{LH}$ and for nine in the RH. The responses of one excluded subject were extremely weak in the $\mathrm{LH}$, and the data of the other excluded subject were very noisy, thus preventing reliable source modeling. The magnetic field patterns evoked by monaural stimuli were modeled by two equivalent current dipoles, one in each hemisphere, to explain signal variability in 26 planar gradiometer channels over each temporal lobe (goodness-of fit $>80 \%$ ). These monaural dipoles were also used to model the corresponding steadystate responses elicited by the frequency-tagged binaural stimuli, and binaural suppression was measured based on peak-to-peak values of the source waveforms.

RNA extraction and cDNA synthesis. RNA samples from 10 ROBO1 subjects were extracted from Epstein-Barr virus (EBV)-transformed lymphocyte cell lines. Control RNA samples from 10 anonymous blood donors, used previously in another study, were extracted from isolated peripheral blood mononuclear cells.

RNA extraction from all samples was performed using RNeasy Plus Mini kit (Qiagen) that includes the removal of genomic DNA with a gDNA Eliminator spin column. The yield and purity of the RNA extracts were measured using a NanoDrop 1000 Spectrophotometer (Thermo Fisher Scientific). cDNA syntheses were performed (900 ng of total RNA in a reaction volume of $50 \mu \mathrm{l}$ ) using Taqman Reverse Transcription Reagents with random hexamer primers (Applied Biosystems).

ROBO1 expression assay. To study mRNA levels of ROBO1, the cDNA samples were subjected to quantitative real-time PCR (qRT-PCR) on an Applied Biosystems ABI Prism 7900 HT Sequence Detection System using predeveloped TaqMan gene expression assays. The samples were run in triplicates with a reaction volume of $10 \mu \mathrm{l}$ on a single 384 -well plate. The threshold cycles (Ct) measured with the ROBO1 assay (Hs00268049_m1) were normalized to the geometric mean of two reference genes, GAPDH (assay 4310884E) and $18 S$ rRNA (assay 4310893E), using the comparative Ct method (all instruments and reagents from Applied Biosystems). For the dose analysis with MEG data, the normalized Ct values $(\Delta \mathrm{Ct})$ were subtracted from the highest individual $\Delta \mathrm{Ct}$ value, resulting in $\Delta \Delta \mathrm{Ct}$ values with logical order, with higher numbers indicating stronger expression. The expression levels of the two $R O B O 1$ transcript variants were measured similarly, using the specific ROBO1a (NM_002941.3, assay Hs01560564_ml) or ROBO1b (NM_133631.3, assay Hs01560560_ml) assays.

Statistical analysis. The results of the control subjects were analyzed by a two-way within-subjects ANOVA. To compare the $R O B O 1$ and control 

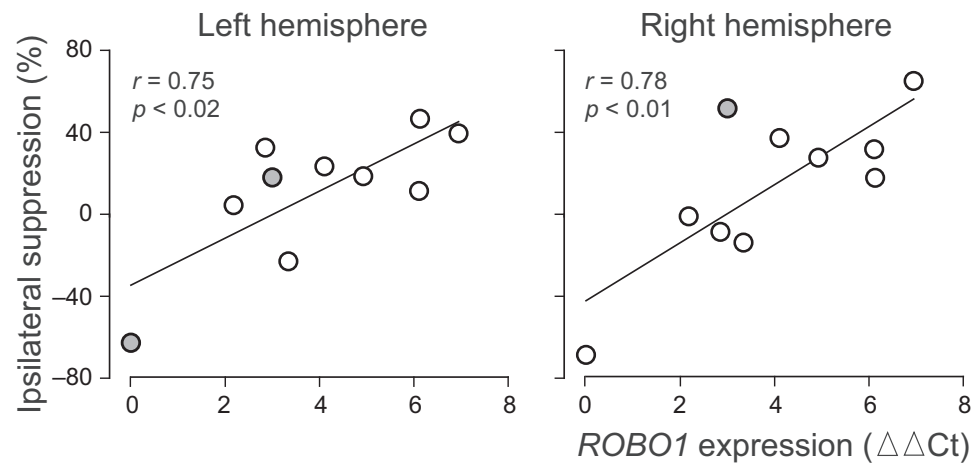

Figure 3. Dependence of the ipsilateral suppression on lymphocyte $R O B O 1 \mathrm{mRNA}$ level in $R O B O 1$ subjects. $R O B O 1$ expression levels are shown as $\Delta \Delta$ Ct values; the higher number indicates stronger expression (Ct in qRT-PCR were normalized first against the geometric mean of GAPDH and 185 rRNA and then against the highest individual value). The regression lines and the correlation coefficients show that decreasing gene expression is associated with weaker ipsilateral suppression in both hemispheres. The additional source analysis of eight subjects in the LH and nine subjects in the RH confirmed the relationship; the subjects with unreliable source modeling are colored gray. levels of their $R O B O 1$, we performed expression analysis by qRT-PCR. RNA used in the qRT-PCR was extracted from lymphocytes, which are commonly used as models of neuronal gene expression (Gladkevich et al., 2004).

In both hemispheres, the ipsilateral suppression weakened along with the ROBO1 gene expression level (Fig. 3; Pearson's correlations in the LH, $r=0.75$, $p<0.02$ and in the RH, $r=0.78, p<0.01$; qRT-PCR results shown as $\Delta \Delta$ Ct values, with higher numbers indicating stronger $R O B O 1$ expression). The expression analysis was performed twice with similar results, and the correlations were confirmed by the additional source analysis of subjects with reliable modeling (eight in the $\mathrm{LH}$, nine in the $\mathrm{RH}$ ). groups, we performed a $2 \times 2 \times 2$ mixed ANOVA design in which subject group was a between-subject factor and ear of stimulation (ipsilateral vs contralateral) and hemisphere ( $\mathrm{LH}$ vs $\mathrm{RH}$ ) were within-subjects factors. For detailed examination of the interaction found in the mixed ANOVA, an additional ANOVA focusing on the ipsilateral suppressions and another ANOVA for contralateral suppression were used.

\section{Results}

\section{Binaural suppression}

In healthy control subjects-in line with previous results (Fujiki et al., 2002; Kaneko et al., 2003)—the sinusoidal steady-state auditory-cortex responses to amplitude modulated tones (Fig. $2 C$, top) were smaller to binaural (dashed lines) than monaural (solid lines) stimulation, especially for inputs from the ipsilateral ear. The binaural suppression was significantly stronger for the ipsilateral than the contralateral inputs $\left(F_{(1,9)}=27.67, p=0.001\right.$, partial $\eta^{2}=0.76$; mean \pm SEM suppression in the LH, $42.5 \pm 6.1$ vs $14.8 \pm 3.7 \%$; in the $\mathrm{RH}, 46.6 \pm 6.4$ vs $14.9 \pm 4.8 \%)$. The hemisphere ( $\mathrm{LH}$ or $\mathrm{RH}$ ) had no main effect on the suppression, and no significant interactions were found.

In contrast to control subjects, $R O B O 1$ subjects showed only minimal ipsilateral suppression of the steady-state responses (Fig. 2C, bottom); accordingly, the mixed ANOVA revealed significant interaction between the subject group ( $R O B O 1$ vs controls) and ear of stimulation (ipsilateral vs contralateral) $\left(F_{(1,18)}=\right.$ $11.79, p=0.003$, partial $\left.\eta^{2}=0.40\right)$. A more detailed evaluation of this interaction demonstrated that the ipsilateral suppression (Fig. $2 \mathrm{D}$, left) was statistically significantly weaker in the $R O B O 1$ group than in the control subjects $\left(F_{(1,18)}=7.78, p=0.012\right.$, partial $\eta^{2}=0.30$; mean \pm SEM suppression, $10.8 \pm 10.2$ vs $42.5 \pm 6.1 \%$ in the $\mathrm{LH}$ and $13.9 \pm 12.2$ vs $46.6 \pm 6.4 \%$ in the $\mathrm{RH})$. Contralateral suppressions (Fig. $2 D$, right) did not differ between the $R O B O 1$ and control groups $\left(F_{(1,18)}=0.30, p=0.59\right.$, partial $\eta^{2}=0.02$; mean \pm SEM suppression, $11.6 \pm 6.7$ vs $14.8 \pm 3.7 \%$ in the $\mathrm{LH}$ and $11.5 \pm 5.5$ vs $14.9 \pm 4.8 \%$ in the $\mathrm{RH}$ ). The additional source analysis (see Materials and Methods) provided practically identical results.

\section{Correlation between ipsilateral suppression and gene expression}

To examine the relationship between the abnormal ipsilateral suppression found in the $\mathrm{ROBO} 1$ subjects and the expression

\section{Expression of $R O B O 1$ transcript variants}

Because $\mathrm{ROBO} 1$ encodes two different proteins of possibly distinct developmental roles, we studied the expressions of a longer transcript variant, $R O B O 1 a$, and a shorter form, $R O B O 1 b$ (aka $D U T T 1$ ) separately. ROBO1 $a$ and $R O B O 1 b$ are derived from the alternative transcription initiation sites and spliced differentially, and they share the majority of the coding sequences (Clark et al., 2002). In mice, Robolb is the predominant isoform, showing wide expression in both neurodevelopment and adult tissues, whereas the expression of Robola is weaker, as well as more temporally and spatially restricted; in adult mice, Robola has been found only in brain, kidney, and eye (Clark et al., 2002; Nural et al., 2007).

In our qRT-PCR analysis, the overall expression of ROBO1 (used in the dose analysis with MEG data) correlated very strongly with the ROBO1b expression (for each analysis, $r>$ 0.99), in line with previous animal studies (Clark et al., 2002; Nural et al., 2007). In contrast, ROBO1a was not expressed in blood at reliable or detectable levels (Ct values $>35$ or undetermined).

We further tested the validity of the isoform-specific assays used in expression analysis in commercially available brain cDNA samples. Both probes showed highest expression in developing fetal brain, and $R O B O 1 b$ was expressed more strongly than $R O B O 1 a$ in all brain areas (data not shown).

\section{$R O B O 1$ expression in healthy control subjects}

We aimed to compare total $\mathrm{ROBO} 1$ expression levels between the $R O B O 1$ subjects and healthy individuals, although the partial haploinsufficiency of the $R O B O 1$ gene [that is, one functional copy and one weakly expressing copy of the gene (HannulaJouppi et al., 2005)] most probably decreases the total biallelic $R O B O 1$ expression only slightly in our $R O B O 1$ subjects. For this additional analysis, preexisting blood samples from 10 anonymous blood donors were exploited. Both the $R O B O 1$ group and the blood donors showed wide variability in the individual expression levels, and no statistically significant difference in the total biallelic expressions between the $\mathrm{ROBO} 1$ subjects and blood donors was found (mean $\pm \mathrm{SD}$ expression in terms of $\Delta \mathrm{Ct}$, normalized against the geometric mean of GADPH and $18 S$ rRNA, $15.9 \pm 2.1$ vs $14.9 \pm 1.7$, respectively). 
Like the $R O B O 1$ group, the blood donors showed undetectable or minimal ( $\mathrm{Ct}$ values $>35$ ) ROBO1a expressions, and the $R O B O 1 b$ expression correlated with the overall $R O B O 1$ expres$\operatorname{sion}(r=0.94)$.

\section{Discussion}

\section{Novel biomarker and a rare family in revealing the functions of $\mathrm{ROBO1}$}

Our combination of an electrophysiological biomarker of auditory pathway crossing with gene expression analysis demonstrated clearly defective interaural interaction in subjects with a weakly expressing haplotype of the $R O B O 1$ gene. Importantly, the extent of the deficit correlated with $R O B O 1$ expression level. The family we examined, which is the only known subgroup of individuals with a rare, specific, weakly expressing haplotype of $R O B O 1$, provided an exceptional opportunity to explore both the role of $R O B O 1$ in the human CNS and the effects of genetic variance on the functions guided by $R O B O 1$. The results demonstrate the significance of the human $R O B O 1$ gene in auditory processing and brain development and link, for the first time, a potential dyslexia susceptibility gene to a specific sensory function of the human brain.

\section{Binaural suppression as a measure of axonal crossing}

The weakened suppression of ipsilateral inputs in the ROBO1 group supports our hypothesis of defective axonal midline crossing caused by partial $\mathrm{ROBO1}$ haploinsufficieny. According to the well-established anatomy of the auditory pathways, the weakened suppression most likely reflects deficient midline crossing in the auditory pathways.

The electrophysiological findings in our $\mathrm{ROBO} 1$ subjects were stronger than what would be expected on the basis of animal studies. Homozygous Robo1 knock-out mice can display large defects in corpus callosum and in other nerve tracts crossing the midline (Andrews et al., 2006); however, in an another knock-out study, only minor defects were detected in corpus callosum (López-Bendito et al., 2007). No reports exist about anatomical abnormalities in heterozygous Robol knock-out mice, evoking the possibility that one normally expressing copy of the Robo1 gene is enough for normal embryonic development (HernándezMiranda et al., 2011). The clear functional defect found in our subjects who have one normal and one weakly expressing allele of ROBO1 (Nopola-Hemmi et al., 2001) could reflect, beyond the sensitivity of the applied electrophysiological method, abnormalities already in the inferior colliculus (IC), a structure important for binaural hearing (Moore, 1991). In rat embryos, Robo1 mRNA has been observed in both IC and the more peripheral cochlear nucleus (Marillat et al., 2002). Of course, small abnormalities along the auditory pathways, for example deficient midline crossing of the auditory axons at several levels, may accumulate along the whole pathway.

In addition to a major role in axonal midline guidance, Robo1 also controls the migration of GABAergic interneurons from telencephalon to rodent cortex (Andrews et al., 2006, 2008; Hernández-Miranda et al., 2011). GABA, as the most important inhibitory neurotransmitter in the mammalian brain, modulates binaurally responding cells in the bat auditory cortex (Razak and Fuzessery, 2010). However, without abnormal crossing, altered GABA-mediated inhibition would be unlikely to produce such strong defects as were found for the ipsilateral inputs.

In our $R O B O 1$ subjects, the abnormal ipsilateral suppression correlated with the $R O B O 1$ expression levels in a dose-dependent manner and in both hemispheres: the weaker the expression, the more abnormal was the interaural interaction.

\section{The roles of splicing variants $R O B O 1 a$ and $R O B O 1 b$}

Our current results, coinciding with the animal studies (Clark et al., 2002; Nural et al., 2007), demonstrate that the expression of the splicing variant $R O B O 1 b$ accounts for the great majority of the overall expression of $\mathrm{ROBO1}$ in adult human lymphocytes. Because the overall expression of $\mathrm{ROBO1}$ is attenuated from the dyslexia-associated allele (Hannula-Jouppi et al., 2005), we conclude that, in $R O B O 1$ subjects, the expression of the shorter transcript, $R O B O 1 b$, is defective. Because the coding sequences of the $R O B O 1 b$ and ROBO1a extensively overlap (Clark et al., 2002), the defective expression of both splicing variants is highly probable. In a dyslexic subject with a translocation disrupting only the ROBOla transcript - not $\mathrm{ROBO} 1 \mathrm{~b}$ - the expression of $\mathrm{ROBO}$ ) b was suggested to be biallelic (Hannula-Jouppi et al., 2005). However, the translocation breakpoint in the intron of $R O B O 1 a$ may also modulate the expression of adjacent ROBO1b. ROBOla is expressed especially in the auditory areas, whereas $R O B O 1 b$ is expressed more evenly throughout the mid-fetal neocortex (Johnson et al., 2009). We were not able to evaluate the expression levels of $R O B O 1 a$, and additional studies are needed for clarification of the different roles of the two splicing variants.

\section{$R O B O 1$ expression in healthy versus $\mathrm{ROBO} 1$ subjects}

According to the previously established partial haploinsufficiency of $R O B O 1$ subjects (Hannula-Jouppi et al., 2005), only small differences in the total biallelic expression levels between the healthy individuals and $R O B O 1$ group were expected. In a previous study (Hannula-Jouppi et al., 2005), the expression of the dyslexia-linked allele was on average $66 \%$ of the expression of the same allele in control subjects, corresponding to $83 \%$ $(=166 \% / 2)$ of normal biallelic expression level and a difference of only 0.27 in $\triangle \mathrm{Ct}$ values between the $\mathrm{ROBO}$ group and control subjects $\left(83 \%=2^{-0.27}\right)$. Notably, ROBO1 expression levels were measured in white blood cells, because no brain cells were available for obvious reasons. Although the dyslexia-linked allele would be totally inactive in all $\mathrm{ROBO} 1$ subjects, meaning that the healthy individuals express $R O B O 1$ on average approximately two times more than $R O B O 1$ subjects, the mean $\triangle \mathrm{Ct}$ value would be approximately one cycle higher in the $R O B O 1$ group than in healthy individuals, as it actually was in our study (15.9 in ROBO1 group vs 14.9 in healthy controls). However, the difference did not reach statistical significance in our group of 10 subjects. The slightly different RNA extraction methods (i.e., EBV-transformed lymphocytes in the $\mathrm{ROBO1}$ group vs peripheral blood mononuclear cells in the control group) most likely had no significant effect on the results because most genes are expressed similarly in those two cell lines (Rollins et al., 2010). Furthermore, the results are well in line with the underlying partial haploinsufficiency.

An extremely interesting question is why healthy individuals behave normally despite large individual variability of total biallelic expression levels, whereas subjects with moderately weakened expression from the other $\mathrm{ROBO1}$ allele show clearly defective auditory processing and abnormal phenotype. Because of temporal and spatial changes in $\mathrm{ROBO}$ expression, the differences in biallelic expression levels between healthy individuals and $\mathrm{ROBO} 1$ subjects may be much more substantial in developing fetal brain than in adult lymphocytes. In addition, some deficits primarily caused by small developmental disorders may be 
accentuated during later development as a result of behavioral abnormalities.

\section{$R O B O 1$ in dyslexia and related disorders}

Among the four currently most noteworthy candidates for dyslexia genes, $R O B O 1$ seems to differ functionally from the three other genes: in rodents, DYX1C1, DCDC2, and KIAA0319 orthologs have no role in axonal midline guidance and tangential migration of interneurons but instead participate in radial migration. In healthy subjects, $R O B O 1$ associates with language deficits, specifically with phonological buffer deficit (Bates et al., 2011). It has also been linked to autism (Anitha et al., 2008). Dyslexia and a specific language impairment (SLI) are comorbid disorders, and early SLI predicts later dyslexia (Snowling et al., 2000). Interestingly, an SLI-related phenotype, speech sound disorder, has shown linkage to the region on chromosome 3 in which $R O B O 1$ is located (Stein et al., 2004). Thus, revealing the roles of $R O B O 1$ in human neurodevelopment seems highly relevant.

\section{References}

Andrews W, Liapi A, Plachez C, Camurri L, Zhang J, Mori S, Murakami F, Parnavelas JG, Sundaresan V, Richards LJ (2006) Robol regulates the development of major axon tracts and interneuron migration in the forebrain. Development 133:2243-2252.

Andrews W, Barber M, Hernadez-Miranda LR, Xian J, Rakic S, Sundaresan V, Rabbitts TH, Pannell R, Rabbitts P, Thompson H, Erskine L, Murakami F, Parnavelas JG (2008) The role of Slit-Robo signaling in the generation, migration and morphological differentiation of cortical interneurons. Dev Biol 313:648-658.

Anitha A, Nakamura K, Yamada K, Suda S, Thanseem I, Tsujii M, Iwayama Y, Hattori E, Toyota T, Miyachi T, Iwata Y, Suzuki K, Matsuzaki H, Kawai M, Sekine Y, Tsuchiya K, Sugihara G, Ouchi Y, Sugiyama T, Koizumi K, et al. (2008) Genetic analyses of roundabout $(R O B O)$ axon guidance receptors in autism. Am J Med Genet B Neuropsychiatr Genet 147B: 1019-1027.

Avadhani A, Ilayaraja V, Shetty AP, Rajasekaran S (2010) Diffusion tensor imaging in horizontal gaze palsy with progressive scoliosis. Magn Reson Imaging 28:212-216.

Bates TC, Luciano M, Medland SE, Montgomery GW, Wright MJ, Martin NG (2011) Genetic variance in a component of the language acquisition device: $R O B O 1$ polymorphisms associated with phonological buffer deficits. Behav Genet 41:50-57.

Brose K, Bland KS, Wang KH, Arnott D, Henzel W, Goodman CS, TessierLavigne M, Kidd T (1999) Slit proteins bind Robo receptors and have an evolutionarily conserved role in repulsive axon guidance. Cell 96:795-806.

Clark K, Hammond E, Rabbitts P (2002) Temporal and spatial expression of two isoforms of the Dutt1/Robol gene in mouse development. FEBS Lett 523:12-16.

Fisher SE, Francks C, Marlow AJ, MacPhie IL, Newbury DF, Cardon LR, Ishikawa-Brush Y, Richardson AJ, Talcott JB, Gayán J, Olson RK, Pennington BF, Smith SD, DeFries JC, Stein JF, Monaco AP (2002) Independent genome-wide scans identify a chromosome 18 quantitative-trait locus influencing dyslexia. Nat Genet 30:86-91.

Fujiki N, Jousmäki V, Hari R (2002) Neuromagnetic responses to frequency-tagged sounds: a new method to follow inputs from each ear to the human auditory cortex during binaural hearing. J Neurosci 22:RC205(1-4).

Gladkevich A, Kauffman HF, Korf J (2004) Lymphocytes as a neural probe: potential for studying psychiatric disorders. Prog Neuropsychopharmacol Biol Psychiatry 28:559-576.

Hannula-Jouppi K, Kaminen-Ahola N, Taipale M, Eklund R, NopolaHemmi J, Kääriäinen H, Kere J (2005) The axon guidance receptor gene $R O B O 1$ is a candidate gene for developmental dyslexia. PLoS Genet 1:e50.

Hari R, Renvall H (2001) Impaired processing of rapid stimulus sequences in dyslexia. Trends Cogn Sci 5:525-532.
Hernández-Miranda LR, Cariboni A, Faux C, Ruhrberg C, Cho JH, Cloutier JF, Eickholt BJ, Parnavelas JG, Andrews WD (2011) Robol regulates semaphorin signaling to guide the migration of cortical interneurons through the ventral forebrain. J Neurosci 31:6174-6187.

Jen JC, Chan WM, Bosley TM, Wan J, Carr JR, Rüb U, Shattuck D, Salamon G, Kudo LC, Ou J, Lin DD, Salih MA, Kansu T, Al Dhalaan H, Al Zayed Z, MacDonald DB, Stigsby B, Plaitakis A, Dretakis EK, Gottlob I, et al. (2004) Mutations in a human ROBO gene disrupt hindbrain axon pathway crossing and morphogenesis. Science 304:1509-1513.

Johnson MB, Kawasawa YI, Mason CE, Krsnik Z, Coppola G, Bogdanović D, Geschwind DH, Mane SM, State MW, Sestan N (2009) Functional and evolutionary insights into human brain development through global transcriptome analysis. Neuron 62:494-509.

Kaneko K, Fujiki N, Hari R (2003) Binaural interaction in the human auditory cortex revealed by neuromagnetic frequency tagging: no effect of stimulus intensity. Hear Res 183:1-6.

Kidd T, Brose K, Mitchell KJ, Fetter RD, Tessier-Lavigne M, Goodman CS, Tear G (1998a) Roundabout controls axon crossing of the CNS midline and defines a novel subfamily of evolutionarily conserved guidance receptors. Cell 92:205-215.

Kidd T, Russell C, Goodman CS, Tear G (1998b) Dosage-sensitive and complementary functions of roundabout and commissureless control axon crossing of the CNS midline. Neuron 20:25-33.

Kidd T, Bland KS, Goodman CS (1999) Slit is the midline repellent for the robo receptor in Drosophila. Cell 96:785-794.

López-Bendito G, Flames N, Ma L, Fouquet C, Di Meglio T, Chedotal A, Tessier-Lavigne M, Marín O (2007) Robol and Robo2 cooperate to control the guidance of major axonal tracts in the mammalian forebrain. J Neurosci 27:3395-3407.

Marillat V, Cases O, Nguyen-Ba-Charvet KT, Tessier-Lavigne M, Sotelo C, Chédotal A (2002) Spatiotemporal expression patterns of slit and robo genes in the rat brain. J Comp Neurol 442:130-155.

Moore DR (1991) Anatomy and physiology of binaural hearing. Audiology 30:125-134

Ng AS, Sitoh YY, Zhao Y, Teng EW, Tan EK, Tan LC (2011) Ipsilateral stroke in a patient with horizontal gaze palsy with progressive scoliosis and a subcortical infarct. Stroke 42:e1-e3.

Nopola-Hemmi J, Myllyluoma B, Haltia T, Taipale M, Ollikainen V, Ahonen T, Voutilainen A, Kere J, Widén E (2001) A dominant gene for developmental dyslexia on chromosome 3. J Med Genet 38:658-664.

Nopola-Hemmi J, Myllyluoma B, Voutilainen A, Leinonen S, Kere J, Ahonen $\mathrm{T}$ (2002) Familial dyslexia: neurocognitive and genetic correlation in a large Finnish family. Dev Med Child Neurol 44:580-586.

Nural HF, Todd Farmer W, Mastick GS (2007) The Slit receptor Robo1 is predominantly expressed via the Dutt 1 alternative promoter in pioneer neurons in the embryonic mouse brain and spinal cord. Gene Expr Patterns 7:837-845.

Razak KA, Fuzessery ZM (2010) GABA shapes a systematic map of binaural sensitivity in the auditory cortex. J Neurophysiol 104:517-528.

Rollins B, Martin MV, Morgan L, Vawter MP (2010) Analysis of whole genome biomarker expression in blood and brain. Am J Med Genet B Neuropsychiatr Genet 153B:919-936.

Seeger M, Tear G, Ferres-Marco D, Goodman CS (1993) Mutations affecting growth cone guidance in Drosophila: genes necessary for guidance toward or away from the midline. Neuron 10:409-426.

Sicotte NL, Salamon G, Shattuck DW, Hageman N, Rüb U, Salamon N, Drain AE, Demer JL, Engle EC, Alger JR, Baloh RW, Deller T, Jen JC (2006) Diffusion tensor MRI shows abnormal brainstem crossing fibers associated with ROBO3 mutations. Neurology 67:519-521.

Snowling M, Bishop DV, Stothard SE (2000) Is preschool language impairment a risk factor for dyslexia in adolescence? J Child Psychol Psychiatry 41:587-600.

Stein CM, Schick JH, Gerry Taylor H, Shriberg LD, Millard C, Kundtz-Kluge A, Russo K, Minich N, Hansen A, Freebairn LA, Elston RC, Lewis BA, Iyengar SK (2004) Pleiotropic effects of a chromosome 3 locus on speech-sound disorder and reading. Am J Hum Genet 74:283-297.

Yuan SS, Cox LA, Dasika GK, Lee EY (1999) Cloning and functional studies of a novel gene aberrantly expressed in RB-deficient embryos. Dev Biol 207:62-75. 